Peter G. Kirchschläger

\title{
Ethics of Blockchain Technology
}

\section{Introduction}

There are no doubts about the innovation-force and the economic potential of blockchain technology. It is the basis for new currencies and financial services, for smart contracts, ... After mainframes, personal computer, the internet, and mobile devices, blockchain technology can be seen as the fifth disruptive computing paradigm (Swan 2015; Polrot 2017).

Outside the blockchain technology-community there are perhaps some questions how blockchain technology exactly works. This aspect can be easily addressed. The only necessary prerequisites are respective knowhow and patience with people without a technological background. There are though ethical questions, which arise in the context of blockchain technology requiring more attention due to their complexity (Kirchschlaeger 2021). This article tries to identify and to discuss them. This ethical analysis legitimated in itself gains even more concrete relevance in front of the background of fundamental criticism(s) blockchain technology or applications based on blockchain technology are facing. E. g., when looking at the use of blockchain in finance: the economist and Nobel Prize laureate Paul Krugman defines the crypto-currency "bitcoin" as "evil" (Krugman 2013), the economist and Nobel Prize laureate Joseph Stiglitz makes the following assessment of crypto-currencies: "You cannot have a means of payment that is based on secrecy when you're trying to create a transparent banking system (...) If you open up a hole like bitcoin, then all the nefarious activity will go through that hole, and no government can allow that. (...) By regulating the abuses, you are going to regulate it out of existence. It exists because of the abuses" (CNBC 2018).

The timing of this endeavor seems to be apropos because blockchain technology is still an emergent technology. Maybe its further design and application could happen in an ethically informed manner ...

Before addressing these ethical questions, a conceptual understanding of what blockchain technology embraces is necessary.

"It consists of a permanent, distributed, digital ledger, resistant to tampering and carried out collectively by all the nodes of the system. The formidable innovation introduced by this technology is that the network is open and participants do not 
need to know or to trust each other to interact: the electronic transactions can be automatically verified and recorded by the nodes of the network through cryptographic algorithms, without human intervention, central authority, point of control or third party (e.g. governments, banks, financial institutions or other organizations). Even if some nodes are unreliable, dishonest or malicious, the network is able to correctly verify the transactions and protect the ledger from tampering through a mathematical mechanism called proof-of-work, which makes human intervention or controlling authority unnecessary." (Atzori 2015, 2)

Blockchain technology thus includes "a shift from trusting people to trusting math” (Antonopolous 2016). Institutional intermediaries providing trust seem to become obsolete. This shift could contain a paradigmatic improvement for science, research, innovation, development, and technology in general by opening a new horizon of open access academic publishing based on blockchain technology - including, e. g., the scientific discourse of which this article is a part. Why? Because blockchain technology guarantees everyone a continuous documentation not belonging to anyone and not being controlled by anyone and an access at all times to review cryptographically verified peer-to-peer procedures, it possesses the potential of changing the process of science, research, innovation, development, and technology fundamentally to a completely open and transparent process. This way it respects the right to intellectual property and in virtue of that, it encourages and motivates free, open, and independent scientific discourse.

Beyond that, blockchain technology can be seen as consisting in another shift - from an internet of information to an internet of value (Swan 2015). Although one could argue that value can be broken down to information and therefore this shift should be framed differently, Melanie Swan and Primavera De Filippi highlight adequately "the secure, end-to-end and computationally validated transfer of value (whether it is represented by money, assets, or contractual arrangements) via smart networks" (Swan and De Filippi 2017, 605; see also Storino, Steffen and Gordon 2017) as an innovative nucleus of blockchain technology. Therefore, the shift should be defined differently, namely a shift from an intermediated network to an immediate network.

The ethical analysis of blockchain technology in this article proceeds in a hermeneutic and fundamental framework of understanding the correlation between ethics and technology in a context partly created by technology as based on reciprocity: both - ethics and technology - contribute to each other. This correlation between ethics and technology starts from the premise that ethics are based on "an interaction with technology" because 
ethical discourse of technology depends on the understanding that technology is "something made" and "not anything given" (Heesen 2014).

This understanding of the correlation between ethics and technology continues by acknowledging that perceiving technological development and process as a linear process pursuing a well-defined scope would probably not correspond to the present-day theory and reality of technology (Kuhn 1962). Technological innovations are rather often the result of small steps and represent regularly random products (Boutellier, Heinzen and Raus 2010, 136). "Technology is not ordinarily developed after carefully considering the various possible ramifications. In most cases a new technology is developed because it promises major short-term benefits and is judged not to cause any immediate problems" (Shibasaki 2005, 489). In addition, the speed of technological advancement outpacing normative considerations represents another characteristic of the way technology functions. Furthermore, some norms exist by dint of certain technological developments. Besides that, its complexity should not be underestimated (Dorn and Van de Poel 2012, 2). Beyond that, ground-breaking ideas in technology and their successful application provoke a concrete impact in ethics as technology creates value, solutions for societal challenges, and innovation (Lucchi 2016 , 6). One would need to go even further by perceiving the impact of technology even on implicit norms, attitudinal orientations, comportment, and even intangibles of human experience reified as concrete features of reality. Even specifically along the moral dimension, technology leads to innovation and dynamics because the societal and individual transformation based on technology needs to be taken into account in ethics as well (Kernaghan 2014). Finally, smart technology is influencing (e. g., by nudging) (Mathis and Avishalom 2016) at least individual lives - if not even the ethical dimension of individual lives (Guthrie 2013).

At the same time, ethics contributes to technology, e. g., by stimulating technological innovation (Lucchi 2016, 7), by recognizing technological inventions (Lucchi 2016, 1f), and by providing ethical guidance (Rainey and Goujon 2011). One needs to go even further stating that ethics belongs to technology. "The idea of scientific knowledge as value-neutral is simply incorrect. Values are intrinsic to the making of science and technology, and they both reflect and transform particular values" (De Melo-Martín 2010, 9). Horizons of meaning and moral ends inform technology in an ethical sense. Beyond that, while the technology-community is aware of its legal obligations and legal compliance standards, it strives for the respect of ethical principles in its work as well, e. g., honesty, objectivity, independence, impartiality, fairness, responsibility for future generations. 
Furthermore, ethics can critically examine the legal obligations and legal compliance standards of the technology-community on a regularly basis. This should (ideally) lead to a continuous optimization of the legal framework for technology. Besides, ethics can help in the process of agenda-setting in technology not only in defining the right priorities but also in framing adequately the sphere of influence and responsibility of technology.

Finally, while technology contributes to the progress of ethics, it is obvious that at the same time there is need for ethics in technology in order to be able even to conduct the necessary research, discussions, and studies. Technology can be the victim of infringements of its freedom, of attempts to block innovative and creative approaches, and of oppression of ideas, concepts, and discoveries. Reasons for these transgressions can be putative "absolute truths" or the enforcement of economic or political totalitarian power structures. The danger still exists of members of the technology-community being prevented from conducting their research freely and independently. Therefore, there is a need for legal and ethical norms supporting and protecting technological progress.

This reciprocal correlation between ethics and technology recognizes the aspect as well that ethics can limit technology. E. g., health- and safety-guidelines, patents, legal ownership of intellectual property rights, competition policy, consumer protection, and ethical codes of conduct belong to this category. This impact by ethics can be perceived as blocking and hindering technological innovation. Ethics is challenged more and more not only by human curiosity striving for new inventions and solutions but by linked substantial economic interests and power. The defence of the ethically justifiable position that not everything which is doable is ethically good meets the opposition of potential benefits and economic incentives. Due to constantly increased creation of an artificial world and of "a technological simulacrum of natural life" (Jennings 2010, 26) and the corresponding power and influence of humans, the significance of ethics is even growing.

\section{2. "Dual Use"}

Before analyzing blockchain technology more precisely from an ethical standpoint, an initial more general dimension needs to be introduced linked with research, development, innovation and technology: Every innovation and technology - including blockchain technology - embraces the ethical chance serving a legitimate cause and runs the risk of being applied also for illegitimate purposes. This can be illustrated with nuclear techno- 
logy (Badash 1995). This concept of "dual use" emphasizes that innovation, scientific knowledge, or technology per se is not automatically ethically positive but needs to undergo an ethical examination in order to prove if this is the case or not. "Given the immense ambiguities of innovations, in themselves and in their consequences, the ethical scrutiny of innovation is a dictate of reason that should not be ignored any longer" (Enderle 2014). Addressing the challenge of "dual use" is only one part of ethics as the procedural importance of ethics in this specific situation of "dual use" is "after the fact". Generally, the procedural importance of ethics should be at the forefront of the conceptual development workflow as mentioned above in the introduction.

Obviously, the concept of "dual use" covers more than a "deviation of intent" (DiEuliisand Giordano 2018, 239) because the possibility needs to be taken into consideration that a research- or innovation-process could be started as well with an ethically negative aim. Therefore, we cannot automatically assume that every technology-development strives to be ethically beneficial.

The concept of "dual use" covers less than a "dual use dilemma" as the US National Research Council conceptually framed it (Imperiale and Casadevall 2015) because it does not possess necessarily a dilemmatic structure. An ethical scrutiny is able to differentiate the ethically positive from the ethically negative side, which allows the establishment of legal measures supporting the former and preventing or forbidding the latter. The regulatory conceptual framework, entitled "dual use research of concern" (DURC), applied by national and international organizations including the US National Institutes of Health (NIH) and the World Health Organization (WHO) highlights the relevance of considering the phenomenon of "dual use". Therefore, an ethical analysis of blockchain technology needs to take into account the possibility that blockchain technology could be used for legitimate and illegitimate purposes. But which ethical principles do provide guidance for the distinction between legitimate and illegitimate purposes?

\section{Ethical Points of Reference}

These ethical points of reference need to satisfy the requirement of a rational ethics or morality - the fulfilment of the principle of generalizability by presenting rational and plausible arguments - "good reasons". "Good reasons" means that it must be conceivable that all humans, given their 
effective freedom and autonomy as well as their full equality, would agree upon these reasons - within a model of thought and not within a real worldwide referendum - on ethical grounds. (Kirchschlaeger 2021) Being aware of the fact that, of course, they are not the only ethical principles which could help to find ethical guidance in dealing with blockchain technology, and that they do not represent an exhaustive list, it serves the scientific integrity and the aspired argumentative force of this analysis to identify them and the reasons for their selection right at the beginning in a transparent way. "Justice", "responsibility", and "human rights" will be suggested in the following as ethical points of reference because their normative validity can be morally justified (Kirchschlaeger 2013a; Kirchschlaeger 2014a; Kirchschlaeger 2016a) and because of their fundamental character.

\subsection{Justice}

The principle of justice strives for equal treatment and for the attribution of what one is entitled to. Four concepts of justice can be differentiated (Koller 2005). They enable the implementation of justice in a specific and individual situation and context: 1. exchange-justice (e. g., to perform services and to reciprocate); 2. political justice (procedural; fair and unbiased democratic opinion-forming- and decision-making-processes which respect the rights of every individual and enable social cooperation); 3. corrective justice (e.g., remedies in order to correct wrong-doings, rehabilitation, punishment); 4. distributional justice (same distribution of common goods [e. g., education-opportunities, access to the labor-market, perspectives of income] or common burdens [e. g., taxes]). Of course, the choice of a specific concept of justice and the choice of the criterion applied to this specific concept - e.g., effort, need, or equality - influence the understanding of the principle of justice. In addition, all four concepts of justice can be understood from the perspective of "social justice" striving for a just order balancing the interests of groups and individuals and bringing them into a just relation (Glatzel 2000, 148). This differentiation in four concepts and the perspective of social justice build the broadness and depth of the principle of justice. With this differentiation, the following challenge arises: the same situation, decision, or action could be assessed as just and unjust at the same time - depending on the justice-concept of the perspective. E. g., if we imagine a situation where the access to the benefits of blockchain technology is open to the consumers who pay more, this situation can be assessed as just from the standpoint of exchange-justice, and at the same 
time as unjust from the standpoint of distributional justice. Therefore, there is a necessity of clarification.

A first step of a solution (Kirchschlaeger 2013a) entails understanding all four concepts within the perspective of social justice - the latter as a leading principle. Secondly, these four concepts of justice need to be combined in order to avoid a one-sided justice-approach and in order to reach a holistic understanding of justice. All four concepts of justice are brought into a negative cooperation. While a positive cooperation would always entail the inclusion of all four concepts of justice, a negative cooperation embraces the necessity of inclusion of all four concepts of justice, and accordingly the necessity to present rational reasons, if any, respective to several concepts of justice, are not included. This way, justice is understood as omni-dynamic (referring to the cooperation of all four concepts). Thirdly, the above-mentioned principle of social justice is considered, which leads to an understanding of an omni-dynamic social justice (Kirchschlaeger 2013a). This understanding of an omni-dynamic social justice should master the challenge mentioned above (that the same situation, decision, or action can be assessed as just and unjust at the same time, depending upon one's justice-concept) by holding the four justice-concepts in dynamic equilibrium within the hermeneutical framework of social justice.

\subsection{Responsibility}

Responsibility (Kirchschlaeger 2014a) is an ethical principle on which decision-making and action are based, which embraces the relation between a subject of a decision or action and a concerned object of a decision or action (individual, humans, consequences of a decision or action) in a certain form (monadic: responsibility; dyadic: responsibility for the action; triadic: responsibility for the action towards somebody) with a certain volume (sole responsibility, shared responsibility, intensity, sphere of responsibility) of a certain kind (cognizance, accountability-responsibility, liability-responsibility, retrospective consequences-responsibility, prospective providence- or prevention-responsibility) referring to a scale of a judging authority. In order to be a subject of responsibility, one must be free and rational (Nida-Rümelin 2011, 14-18).

Facing the increased complexity of the digital transformation of society and economy, the identification of these above-mentioned dimensions of responsibility (e. g., subjects of responsibility, objects of responsibility) and the relations of responsibility provide ethical orientation (Jonas 1981). 
These identifications are necessary in order to avoid a lack of moral and legal accountability in the case of accidents and crimes and in order to enable risk-assessments, rules for liabilities, and insurances meeting this ethical challenge.

\subsection{Human Rights}

Human rights represent a minimal standard that enables survival and living with human dignity for every human (Kirchschlaeger 2013b, 194f). Human rights are neither maximal moral claims nor a higher ethos. This means that they do not overburden technology. Instead, they are achievable for technology. Human rights have a precise focus which can enhance a clear setting of priorities based on the minimal standards which must first be respected. Therefore, human rights can help in the process of agenda-setting in technology not only in setting the right priorities but also in defining adequately the spheres of influence and responsibility (Kirchschlaeger 2013c, 17). Human rights in their moral dimension (Kirchschlaeger 2013d) can serve as an ethical principle because they are morally justifiable e. g., based on the principle of vulnerability (Kirchschlaeger 2013b; Kirchschlaeger 2016a) - and represent a universally applicable consensus. The latter means that no other catalogue of norms enjoys the same amount of global acceptance. They enjoy credibility and are a widely respected ethical standard.

In addition, human rights do not build upon a particular tradition, culture, religion, worldview or value-system (Gut 2008 and Joas 2015, 71-80). As a consequence, a globalized technology-community finds its orientation with human rights as an ethical point of reference (Kirchschlaeger 2013c) facing several traditions, cultures, religions, worldviews, value-systems, and philosophies. While this heterogeneity is on the one hand protected by human rights (Kirchschlaeger 2013e), it gives this heterogeneity, on the other hand, clear limits which need to be respected: human rights protect the essential elements and areas of human existence within traditions, cultures, religions, worldviews, and value-systems as well. Therefore, human rights can support technology when it is acting in favor of human rights but meeting tradition, culture, religion, worldview, and value-system-based challenges (Kirchschlaeger 2015a).

Furthermore, human rights possess a high degree of practice-orientation and applicability. Compared with other ethical principles, human rights embrace not only the ethical but also the legal dimension: human rights are 
legally defined, have a legal framework, are executable and provide some of the formal structure of the implementation of the rule of law, constraining its implementation by means of setting parameters for its implementation.

Beyond that, the individuals involved in technology are protected by human rights in essential areas and elements of human existence which a human needs for survival and for a life as a human - some of them of specific significance for technological inquiry, research, development, and applications, e.g., the right to freedom (art 2); the right to freedom of thought, conscience and religion (art 18); the right to freedom of opinion and expression (art 19); the right to freedom of peaceful assembly and association (art 20); the right freely to participate in the cultural life of the community, to enjoy the arts and to share in scientific advancement and its benefits (art 27[1]), and the right to the protection of the moral and material interests resulting from any scientific, literary or artistic production of which he is the author (art 27[2]) of the Universal Declaration of Human Rights of 1948.

Limits to one's own human rights are, firstly, - in the case of a specific human right - the other specific human rights following the principle of indivisibility. This principle defines that all human rights must go hand in hand. This means that the entire catalogue of human rights needs to be respected. Therefore, every human right must be implemented optimally and in a way that accords with all other human rights being implemented optimally at the same time. Secondly, limits to one's own human rights are the human rights of all other individuals. For example, one's own right to freedom goes only so far as it can go hand in hand with the right to freedom of all other human beings. Both limits lead also to corresponding duties for a rights-holder which is the reason why every right-holder is a duty-bearer as well (Corillon 1989).

\section{Chances of Blockchain Technology from an Ethical Perspective}

\subsection{Democratic Chances}

Looking at blockchain technology from an ethical standpoint and taking into account especially one main characteristic of blockchain technology, namely decentralization (“'[d]ecentralization’ describes conditions under which the actions of many agents cohere, and are effective despite the fact that they do not rely on reducing the number of people whose will counts to direct effective action" (Benkler 2006, 62)), it is possible to identify - 
especially with human rights as ethical point of reference but only under the condition of respect for the state and for the rule of law - as an ethically positive element of blockchain technology the democratic chances it represents. For a democratic system, blockchain technology could provide censorship-resistant organizational models and a decentralized repository for identity-verification. Furthermore, it could enable state-authorities to become more efficient and effective in providing their services by relying on decentralized self-evolving digitalization (Adams, Kewell and Parry 2018, 134f).

In addition, blockchain technology could help to overcome challenges arising for democracy due to lack of integrity among political leaders and decision-makers. By, e. g., documenting both the promises of election-campaigns and their realization as the consistence in political positions defended by politicians, it could enable trustworthy and content-based political representation. Beyond that, it could open a horizon of transparency of influence by, e.g., documenting the financial support of politicians, of political parties, and of political campaigns. (Crichton2018) Both - trustworthy and content-based political representationand - could increase citizen's active political participation as motivating factors. This impact is even increased by the possibility that generally the blockchain technology itself is open for being shaped by the participating entities (Evans 2014).

Finally, blockchain technology can be categorized - in the framework by Langdon Winner (Winner 1980) - as belonging to "inherently political technologies, man-made systems that appear to require, or to be strongly compatible with, particular kinds of political relationships" (Winner 1980, 123) because due to its decentralized nature, blockchain technology calls for a democratic system rather than for a repressive autocracy. In order to illustrate this aspect further, contrariwise, the nuclear bomb "as it exists at all, its lethal properties demand that it be controlled by a centralized, rigidly hierarchical chain of command closed to all influences that might make its working unpredictable. The internal system of the bomb must be authoritarian" (Winner 1980, 131).

A condition for the realization of these democratic chances of blockchain technology and due to the fact that "blockchain technologies (are) not merely a technical matter, but that it strongly relates to the ways in which we normatively construct, or rather configure our social world" (Reiijers and Coeckelbergh 2018, 127), there is a necessity to "explore how we can implement them in a way that empowers people but that also leaves room for mitigating the potential dangers they bring about. This will require investigating how the governance of the design and use of these 
technologies can be improved, for instance by looking at ways in which the design process can be organized in a more democratic way" (Reiijers a, Coeckelbergh 2018, 127).

\subsection{Transparency, Verifiability, Immutability, and Traceability}

Transparency - not only in the political sphere - represents another ethically positive aspect of blockchain technology if we apply the ethical point of reference of responsibility. As an open-source code, blockchain technology offers everyone anytime an access to review cryptographically verified peer-to-peer procedures - instant "real-time transparency" (Seele 2016). Therefore, blockchain technology offers verifiability: "Transactions are immediately auditable in real time. As an immutable and sequenced digital ledger, a Blockchain allows the complete record of transactions to be directly verified" (LaPointe and Fishbane 2018, 53).As this open-source code does not belong to anyone or is not controlled by anyone (Atzori $2015,7)$, blockchain technology fosters transparency by excluding undisclosed influences or censorship by the owner or by the controlling entity. Besides that, it enfolds immutability because all nodes keep simultaneously and constantly the data and provide the proper redundancy (Atzori 2015, 7). Both - transparency and immutability (Swan and De Filippi 2017, 603f) - lead to traceability provided by blockchain technology, which serves responsibility as an ethical point of reference as it allows identifying the dimensions of responsibility (e. g., the subjects and objects of responsibility), the relations, and the spheres of responsibility. Blockchain technology could be applied in this way in the management of supply chains (Steiner 2015; Adams, Kewell and Parry2018, 134) but also in the fight against human rights violations in supply chains (Kirchschlaeger 2017a; Kirchschlaeger 2017b; Kirchschlaeger 2015b).

\subsection{Economic Potential}

Blockchain technology could provide - among others - access to money and to financial services for about two billion people without a bankingrelation (PriceWaterhouseCoopers 2016). Linked with its economic potential (World Government Summit 2017; Aste, Tasca and Di Matteo 2018; International Monetary Fund, Money 2018; Adams, Kewell and Parry $2018,135)$ is its ethically positive aspect from a human rights perspective. One can argue that having access to minimum basic financial services 
(money, a minimum credit, a saving account, and low-cost money-transferoption) contributes to the respect and to the realization of human rights. The main reasons for this position is the significant role financial resources play in the daily life of humans as means which allow reaching several aims including essential elements and areas of human existence which a human needs for survival and for a life as a human and which are protected by human rights. Besides that, as developments of the financial markets have an impact on the daily life of everyone, above all: on the daily lives of the poor, therefore, everyone should at least have the possibility to participate in the financial markets. Beyond that, the access to certain financial services could be an instrument to overcome illegitimate global inequality and would fulfil the "gap-closing-principle": "Financial institutions and financesystems contribute to global justice if they contribute to the realization of human rights of all humans and if they contribute to the closing of the gap between poor and rich" (Kirchschlaeger 2016b, 550). While maintaining in a greatest possible way the economic rationale of pursuing one's own particular interest, the "gap-closing-principle" introduces the perspective of the poor only as a corrective of the "ad infinitum" of the pursuit of one's own particular interest(s).

Beyond that, crypto currencies could provide financial security in contexts of unstable local currencies which is not only of economic but also of ethical relevance by contributing to the realization of justice as an ethical point of reference.

Finally, with its potential role in land titling and property transactions to whom a significant role in economic development can be attributed (De Soto 2003), blockchain technology could contribute to economic development especially in developing contexts - again of significance from a justice but also from a human rights perspective (De Soto and Cheneval 2006).

\subsection{Health Impact}

Blockchain technology can serve the realization of the human right to health by providing the possibility of decentralized storage of and access to the personal health record (consisting, e. g., also of genomic data) which would allow personalized, more independent, precise, efficient, and effective health care. This innovative attempt to contribute to the realization of the human right to health must of course respect the human dignity of all humans (and therefore distance itself from instrumentalizing or objectivation of humans), it must respect the human right to privacy - based on the 
principle of indivisibility of human rights (Kirchschlaeger2014b) -, it must honor data-protection and the right to informational autonomy, it must overcome the significant challenges of big data "volume - velocity - variety - veracity" (Helbing 2015, 3), and it must address the risk of big data of being a source of systematic discrimination.

\section{Challenges of Blockchain Technology from an Ethical Perspective}

\subsection{Ecological Dimension}

Aiming at the ethical point of reference of human rights - more specifically, the right to life, the right to health, work-related rights, the right to an adequate standard of living incl. the right to housing, food and water, to name just a few (Kirchschlaeger 2012) - and the ethical point of reference of justice - more specifically intergenerational justice -, the enormous energyconsumption of the proof of work consensus method (Boehme, Christin, Edelman and Moore2015) is ethically problematic (Morgan Stanley 2018). E. g., for Bitcoin, for reaching the validity of a proof of work a billion Watts are estimated to be necessary (Aste 2016). Or in another words, "currently, global power demand from cryptocurrency mining hovers at about 22 terawatt hours (TWh), but increasing demand means consumption could surge in 2018 to $125-140 \mathrm{TWh}-$ a full $0.6 \%$ of world consumption. Although that level is still far from material to global utility power demand, it's worth noting that $0.6 \%$ is roughly the electric consumption of Argentina in a typical year" (Morgan Stanley 2018).

Attempts to resolve this ecological problem of blockchain technology consist in making "mining" greener or circumventing the mining process.

"User lock up quantities of cryptocurrency for periods of time, which secures blockchain used by that currency. In return, they receive cryptocurrency rewards, as if they had mined cryptocurrencies themselves" (Kugler $2018,17)$. As this approach is still depending on "mining" in the first place, it does not seem to extinct the ecological problems of blockchain technology. "Some people wonder if crypto-currencies will disrupt the financial system, while others wonder if they will break the environment in the process" (Kugler 2018, 16). 


\subsection{Money Laundry and Financing International Crime and Terrorism}

Blockchain technology faces the ethical problem - which becomes obvious while orienting oneself towards the ethical points of reference of responsibility, justice, and human rights - of being represented or utilized as a technological basis for crypto-currencies, and thereby as a means of laundering money with impunity (e. g. Wall Street Journal 2018).

Crypto-currencies - relying on blockchain technology - are also used for funding international crime and terrorism (The Washington Post 2018) again, obviously, ethically unacceptable based on the ethical points of reference of responsibility, justice, and human rights (Seele 2018; Dierksmeier and Seele 2018).

An obvious criticism arises together with some doubts questioning the positive impact by blockchain technology, namely economically empowering people, and the ethically positive characteristics of blockchain technology above-mentioned, namely: transparency, immutability, and traceability. If those exist, then countermeasures against money laundering and financing international crime and terrorism should be easily implementable, enforceable, and successful. At this point - with the principle of responsibility as ethical guidance - the problem of subjectivity of responsibility in blockchain technology emerges from an ethical standpoint. Who is the subject of responsibility? How can the dimensions of responsibility be identified? Which relations of responsibility exist? How far does this extend the sphere of responsibility? Identifying them represents a complex task. The identification of subjects of responsibility should still be implemented in order to build an atmosphere of liability and accountability - not only out of respect for the objects of responsibility. Complexity cannot serve as an excuse liberating one from legal or ethical obligations and responsibilities because ethical and legal norms keep their validity even in complex situations and contexts.

There is a need for further research and innovation in the area of blockchain technology striving for "ethically guided cryptocurrency systems whose behaviors are informed by human ethical values" (Gladden 2015, 96), for "a successfully functioning 'crypocurrency with a conscience" (Gladden 2015, 96). 


\subsection{Human Rights Violating Excavation of Resources and Production of Technology}

As the ways in which natural resources for the production of technologies and technology-based applications are excavated and exploited, and as the ways in which technologies and technology-based applications are produced consisting of modern slavery and slavery-like working conditions, an increase in the demand for these natural resources by the use of blockchain technology will also increase these human rights violations. The increased demand for natural resources fuelling the dissemination of blockchain technology calls for optimizing the implementation of already existing human rights-obligations of states and the private sector in this area (Kirchschlaeger 2015b).

\section{Right to Privacy}

On the one hand, blockchain technology generates a solution how digitalization and digital transformation can be pursued without violating the right to privacy by providing the technological basis for an independence of digital activity from technology-firms harvesting data and offering them for sale to companies. Blockchain technology allows one to be online without being surveilled, monitored, analyzed - without becoming a product, which then is sold to others without informed consent.

On the other hand, blockchain technology remains a technology-based infrastructure, which of course knows an origin, an owner, and a provider. "Technological considerations weigh heavily on the assessment of the exact degree of anonymity" (Dierksmeier and Seele 2018, 7). This means at the same time that it is technically not excluded that someone is able to gain access to individual online-activity and presence. On the occasion of the fiftieth anniversary of the UN-Covenant against Racism on December 2, 2015, Jan Eliasson, Deputy UN-Secretary General, stated: "Our lives, as you all know, are increasingly lived online. And so we must ensure that our values are alive online as well" (UN 2015). His words were directed immediately to the issue of racism and discrimination on the internet but their core message goes beyond that: Human rights as legal standards and ethical principles are universally valid and must be respected, protected, implemented, and realized even in a digitalized, automatized, robotized society and economy where blockchain technology is used. This is ethically justified because human rights and their universality can be - as above 
mentioned - ethically justified, e. g., based on the principle of vulnerability (Kirchschlaeger 2013b; Kirchschlaeger 2016a). Another pragmatic reason for their validity originates in the drafting process of the legal human rights treaties based on the Universal Declaration of Human Rights of 1948 and consists of the following, already at that time existing consciousness which influenced the drafting of the human rights-documents: "The members of the Commission must take into account the fact that their work concerned the future and not the past; no one could foresee what information media would be employed in a hundred years' time" (Commission on Human Rights 1950) ${ }^{1}$.

Finally, the dynamic character of human rights needs to be emphasized at this point. Human rights have always been open to adaptation in order to stop and prevent new risks, dangers, and violations of human dignity. Therefore, human rights are ready to adapt to future challenges (Kirchschlaeger and Kirchschlaeger 2010). Ethical and legal standards in general can be adopted in order to meet new challenges.

\section{Global Impact of Blockchain Technology: More Inequality?}

There exists the above-mentioned potential to contribute to the creation of more global equality by offering more people access to financial services and markets. By taking into consideration the impact of blockchain technology on the economy so far, though another scenario comes into play, namely that blockchain technology runs the risk to serve as a vehicle contributing to widening the gap between rich and poor. This could happen due to the lack of access to blockchain technology and would strengthen already established privileged positions. This would mean also that fewer people are directly involved economically and socially in a more efficient and more effective value-added chain (Kirchschlaeger 2016c). On the one hand, this development characterizes that more value will be created. On the other hand, fewer people contribute directly to the value-added chain and benefit from this added value. The main challenge from an ethical perspective is therefore not a lack of financial means because more efficient and more productive value-added chain based on blockchain technology lead to an increase in that regard, but rather the question of justice and human rights.

1 French Delegate to the Sixth Commission on Human Rights, 'discussing the "media" clause of the article on freedom of expression in the draft human rights covenant on May 2, 1950'. Commission on Human Rights. 6th Session, 165th mtg. at 10, U.N. Doc. E/CN.4/SR.165 [May 2, 1950]. 
At stake is the distribution of the added value, which is created, respectively, at the center of concern(s). It is the question of social integration as fewer people are involved in the value-added chain based on blockchain technology - a concern which represents the core consequence of digital transformation in general (Kirchschlaeger 2019).

\section{Concluding Remarks: Blockchain Technology's Ambiguity and the Relevance of More Ethical Reflection}

In this article, it became obvious that blockchain technology can serve ethically good purposes and can lead to ethically bad consequences - depending on the concrete applications and solutions based on blockchain technology. At the same time, ethical research is facing the challenge consisting in the ambivalence that even an ethically legitimate application based on blockchain technology can have two sides: besides the ethically legitimate one, another ethically illegitimate side. Beyond that, also in the area of blockchain technology, ethics has to deal with the "dual use"-problem.

Finally, blockchain technology as an immediate network - not an intermediated network - has implications for its ethical assessment with "responsibility" as the ethical point of reference. Due to the lack of intermediaries (as a unique feature of blockchain technology), the responsibility for the blockchain lies in the hands of the immediately connected participating entities because there is not any intermediary institution carrying the burden of responsibility for them.

This outlined ethical complexity of blockchain technology calls for ethical guidance in order to be able to benefit from the chances and meet the challenges of blockchain technology. This article tries to contribute to mastering this challenge by addressing some ethical questions, which arise in the context of blockchain technology, and by providing some ethical guidance in the area of blockchain technology - both by transparently introducing and by concretely applying justice, responsibility, and human rights as ethical points of reference. Further research-contributions in this area are necessary - also for a fundamental reason serving as a horizon of understanding: The ethical responsibility of humans for blockchain technology cannot be delegated to blockchain technology itself due to the moral capability of humans. Even though humans are more and more excluded from value-added chains, they remain the decisive and leading instance for these processes due to their moral capability. Blockchain technology-based applications can follow and implement heteronomously predefined norms 
(Wallach and Allen 2009) but they do not possess moral capability to define autonomously moral norms which are universalizable (Kirchschlaeger 2017c), and they lack autonomy, freedom, and conscience (Kirchschlaeger $2017 \mathrm{~d}$ ). For the same reason one would deny technological systems autonomy and moral capability (Kirchschlaeger 2017e) even if they pretend to decide and to act as if they were moral actors (Wallach and Allan 2009). It is up to humans to provide guidance to blockchain technology, define the speed and outreach of its progress (Krenn 2016, 17) by setting ethical principles and norms and by remaining liable for the decisions and actions of blockchain technology-based applications because of their moral capability. Part of this moral capability is to include ethical principles and categories in the design and programming of blockchain technology and to interact continuously with technological progress (Wallach, Allen and Smith 2008). This ethical responsibility of humans is even growing due to constantly increased creation of an artificial world and of "a technological simulacrum of natural life" and the corresponding power and influence of humans. "If there is one thing the great institutions of the modern world do not do, it is to provide meaning. Science tells us how but not why. Technology gives us power but cannot guide us as to how to use that power. The market gives us choices but leaves us uninstructed as to how to make those choices. The liberal democratic state gives us freedom to live as we choose but refuses, on principle, to guide us on how to choose" (Sacks 2015, C1-C2) Humans need to live up to the responsibility corresponding to that freedom.

\section{Bibliography}

Adams, Richard, Beth Kewell, and Glenn Parry. 2018. "Blockchain for Good? Digital Ledger Technology and Sustainable Development Goals." In Handbook of Sustainability and Social Science Research, edited by Walter Leal Filho, Robert W. Marans, and, John Callewaert, 127-140. Cham: Springer.

Antonopolous, Andreas. 2016. "Bitcoin Security Model: Trust by Computation.” Published June 3, 2016. https://medium.com/@aantonop/bitcoi n-security-model-trust-by-computation-d5b93a37da6e.

Aste, Tomaso, Paolo Tasca, and Tiziana Di Matteo. 2018. "Blockchain Technologies: The Foreseeable Impact on Society and Industry." Computer 50 (9) 18-28.

Aste, Tomaso. 2016. "The fair cost of bitcoin proof of work." https://ssrn.co $\mathrm{m} / \mathrm{abstract}=2801048$ or http://dx.doi.org/10.2139/ssrn.2801048. 
Atzori, Marcella. 2015. "Blockchain Technology and Decentralized Governance: Is the State Still Necessary?" (December 1, 2015). https:/ /ssrn.com/abstract=2709713 or http://dx.doi.org/10.2139/ssrn.2709713. Badash, Lawrence. 1995. Scientists and the development of nuclear weapons: from fission to the Limited Test Ban Treaty.1939 - 1963. London: Humanities Press Intl.

Benkler, Yochai. 2006. The Wealth of Networks: How Social Production Transforms Markets and Freedom. New Haven: Yale University Press.

Boehme, Rainer, Nicolas Christin, Benjamin Edelman, and Tyler Moore. 2015. "Bitcoin: Economics, Technology, and Governance." Journal of Economic Perspectives 29 (2): 213-38.

Boutellier, Roman, Mareike Heinzen, and Marta Raus. 2010. "Paradigms, Science, and Technology: The Case of E-Customs." In Cases on Technology Innovation: Entrepreneurial Successes and Pitfalls, edited by Shirley Ann Becker, and Robert E. Niebuhr, 134-155. Hershey: Business Science Reference.

Commission on Human Rights. 1950. 6th Session, 165th mtg. at 10, U.N. Doc. E/CN.4/SR.165 [May 2, 1950].

CNBC. 2018. "Nobel-winning economist: Authorities will bring down 'hammer' on bitcoin." Published July 9, 2018. https://www.cnb c.com/2018/07/09/nobel-prize-winning-economist-joseph-stiglitz-criticiz es-bitcoin.html.

Corillon, Carol. 1989. "The Role of Science and Scientists in Human Rights." The Annals of American Academy of Political and Social Science 506: 129-140.

Crichton, Danny. 2018. "Liquid democracy uses blockchain to fix politics, and now you can vote for it." https://techcrunch.com/2018/02/24/liquid -democracy-uses-blockchain/.

De Melo-Martín, Immaculada. 2010. "The Two Cultures: An introduction and assessment." Technology in Society 32 (1): 5-9.

De Soto, Hernando. 2003. The Mystery of Capital. Why Capitalism Triumphs in the West and Fails Everywhere Else. New York: Basic Books.

De Soto, Hernando, and Francis Cheneval. 2006. Realizing Property Rights. (Swiss Human Rights Book Vol. 1). Zürich: Rüffer und Rub.

Dierksmeier, Claus, and Peter Seele. 2018. "Cryptocurrencies and Business Ethics." Journal of Business Ethics 152: 1-14.

DiEuliis, Diane, and Giordano James. 2018. Gene editing using CRISPR/ Cas9: implications for dual-use and biosecurity. Protein Cell 9(3): 23940. 
http://dx.doi.org/10.1007/s13238-017-0493-4 PubMed.

https://www.ncbi.nlm.nih.gov/pmc/articles/PMC5829273/.

Dorn, Neelke, and Ibo Van de Poel. 2012. "Editors Overview: Moral

Responsibility in Technology and Engineering." Science and Engineering Ethics 18 (1): 1-11.

Enderle, Georges. 2014. "The Theme of the Sixth World Congress of the International Society of Business, Economics, and Ethics in 2016 in Shanghai, China: 'Ethics, Innovation, and Well-Being in Business and the Economy'. Explorations by Georges Enderle.” Published July 22, 2014. http://isbee.org/the-theme-of-the-sixth-world-congress-of-the-inter national-society-of-business-economics-and-ethics-in-2016-in-shanghai-c hina-ethics-innovation-and-well-being-in-business-and-the-econom/.

World Government Summit. 2017. The future of money. Back to the futurethe internet of money.

Evans, David. 2014. Economic Aspects of Bitcoin and Other Decentralized Public-Ledger Currency Platforms. Coase-Sandor Institute for Law \& Economics Research Paper No. 685 (April 15, 2104). https://ssrn.com/abstract $=2424516$ or http://dx.doi.org/10.2139/ssrn.2424516.

Gladden, Matthew E. 2015. "Cryptocurrency with a Conscience: Using Artificial Intelligence to Develop Money that Advances Human Ethical Values." Annales. Ethics in Economic Life 18 (4): 85-98.

Glatzel, Norbert. 2000. „Soziale Gerechtigkeit - ein umstrittener Begriff.“

In Christliche Sozialethik im Dialog. Zur Zukunftsfähigkeit von Wirtschaft, Politik und Gesellschaft. (Festschrift L. Roos) edited by Ursula NothelleWildfeuer, and Norbert Glatzel, 139-148. Bad Neuenahr-Ahrweiler: Vektor Verlag.

Gut, Walter. 2008. „Eine Sternstunde der Menschheit. Die Allgemeine Erklärung der Menschenrechte von 1948." Schweizerische Kirchenzeitung 49. 816-819.

Guthrie, Clifton F. 2013. "Smart Technology and the Moral Life." Ethics \& Behavior 23 (4): 324-37.

Heesen, Jessica. 2014. „Mensch und Technik. Ethische Aspekte einer Handlungspartnerschaft zwischen Personen und Robotern." In Robotik im Kontext von Recht und Moral (Robotik und Recht Bd. III) edited by Eric Hilgendorf, 253-268. Baden-Baden: Nomos.

Helbing, Dirk. 2015. "Societal, Economic, Ethical and Legal Challenges of the Digital Revolution.” Jusletter IT (May 21, 2015). 
Imperiale, Michael J., and Arturo Casadeval. 2015. "A new synthesis for dual use research of concern.” PLoS Med 12(4): e1001813. http://dx.doi. org/10.1371/journal.pmed.1001813.

International Monetary Fund, Money. 2018. Transformed. The future of currency in a digital world. (Finance \& Development, June 2018).

Jennings, Bruce. 2010. "Enlightenment and enchantment: Technology and moral limits." Technology in Society 32: 25-30.

Joas, Hans. 2015. Sind die Menschenrechte westlich? München: Kösel-Verlag. Jonas, Hans. 1981. Das Prinzip der Verantwortung. Versuch einer Ethik für die technologische Zivilisation. Frankfurt: Insel.

Kernaghan, Kenneth. 2014. "Digital dilemmas: Values, ethics and information technology." Canadian Public Administration 57 (2): 295-317.

Kirchschlaeger, Peter G. 2012. "Evolution of the International Environment Law and Position of Child from a Philosophical Perspective." In Changement Climatique: Impacts sur les enfants et leurs droits, editey by Institut Universitaire Kurt Bösch, 73-87. Sion: Institut international des Droits de l'Enfant.

Kirchschlaeger, Peter G. 2013a. "Gerechtigkeit und ihre christlich-sozialethische Relevanz." Zeitschrift für katholische Theologie 135: 433-456.

Kirchschlaeger, Peter G. 2013b. Wie können Menschenrechte begründet werden? Ein für religiöse und säkulare Menschenrechtskonzeptionen anschlussfähiger Ansatz. (ReligionsRecht im Dialog 15). Münster: LITVerlag.

Kirchschlaeger, Peter G. 2013c. "Human Rights as an Ethical Basis for Science." Journal of Law, Information and Science 22: 1-17.

Kirchschlaeger, Peter G. 2013d. „Die Multidimensionalität der Menschenrechte - Chance oder Gefahr für den universellen Menschenrechtsschutz?" MenschenRechtsMagazin 18: 77-95.

Kirchschlaeger, Peter G. 2013e. „Religionsfreiheit - ein Menschenrecht im Konflikt." Freiburger Zeitschrift für Philosophie und Theologie 60: 353374.

Kirchschlaeger, Peter G. 2014a. „Verantwortung aus christlich-sozialethischer Perspektive." Ethica 22: 29-54.

Kirchschlaeger, Peter G. 2014b. "Ethics and Human Rights." Ancilla Juris 9: 59-98.

Kirchschlaeger, Peter G. 2015a. "Adaptation - A Model for Bringing Human Rights and Religions Together." Acta Academica 47: 163-191.

Kirchschlaeger, Peter G. 2015b. „Multinationale Konzerne und Menschenrechte." Ethica 23: 261-280. 
Kirchschlaeger, Peter G. 2016a. "How Can We Justify Human Rights?" International Journal of Human Rights and Constitutional Studies 4: 313329.

Kirchschlaeger, Peter G. 2016b. „Globale Gerechtigkeit aus einer finanzethischen Perspektive." Freiburger Zeitschrift für Philosophie und Theologie 63 (2): 534-552.

Kirchschlaeger, Peter G. 2016c. „Digitalisierung und Robotisierung der Gesellschaft aus theologisch-ethischer Perspektive." Published March 30, 2016. https://www.feinschwarz.net/digitalisierung-und-robotisierung-der -gesellschaft-aus-theologisch-ethischer-perspektive/.

Kirchschlaeger, Peter G., ed. 2017a. Die Verantwortung von nichtstaatlichen Akteuren gegenüber den Menschenrechten (Religionsrechtliche Studien 4). Zürich: Theologischer Verlag Zürich.

Kirchschlaeger, Peter G. 2017b. „Wirtschaft und Menschenrechte.“ In Eine Wirtschaft, die Leben fördert. Wirtschafts- und unternehmensethische Reflexionen im Anschluss an Papst Franziskus, edited by Ingeborg Gabriel, Peter G. Kirchschläger, and Michael Sturn, 241-264. Ostfildern: Matthias-Grünewald-Verlag.

Kirchschlaeger, Peter G. 2017c. „Automatisierung der Mobilität - theologisch-ethische Überlegungen." Published January 13, 2017.

https://www.feinschwarz.net/automatisierung-der-mobilitaet-theologisch-et hische-ueberlegungen/

Kirchschlaeger, Peter G. 2017d. „Die Rede von ,moral technologies': Eine Kritik aus theologisch-ethischer Sicht." Published March 20, 2017.

https://www.feinschwarz.net/die-rede-von-moral-technologies/.

Kirchschlaeger, Peter G. 2017e. „Gewissen aus moraltheologischer Sicht.“ Zeitschrift für katholische Theologie 139: 155-77.

Kirchschlaeger, Peter G. 2019. „Bedingungsloses Grundeinkommen - eine menschenrechtsethische Betrachtung." In Menschenrechten Gestalt und Wirksamkeit verleihen: Making Human Rights Work (Festschrift Manfred Nowak und Hannes Tretter), edited by Patricia Hladschik, and Fiona Steinert, 551-563. Wien: NWV Verlag.

Kirchschlaeger, Peter G. 2021. „Digital Transformation and Ethics. Ethical Considerations on the Robotization and Automation of Society and the Economy and the Use of Artificial Intelligence. Baden-Baden: Nomos.

Kirchschlaeger, Peter G, and Thomas Kirchschlaeger, eds. 2010. Human Rights and Pervasive Computing. (International Human Rights Forum (IHRF) vol. VII). Bern: Staempfli. 
Koller, Peter. 2005. „Zum Verhältnis von Domestischer und Globaler (Un)Gerechtigkeit." Conference Talk: The Diversitiy of Human Rights: Constitution and Human Rights, InterUniversityCentre Dubrovnik, 310 September 2005: manuscript provided by the author.

Krenn, Brigitte. 2016. "Multiuse Tool and Ethical Agent." In A Construction Manual for Ethical Systems. Requirements, Methods, Implementations, edited by Robert Trappl, 11-29. Cham: Springer.

Krugman, Paul. 2013. "The Conscience of a Liberal." Published December 28. 2013. https://krugman.blogs.nytimes.com/2013/12/28/bitcoin-is-evi 1/

Kugler, Logan. 2018. "Why Cryptocurrencies Use So Much Energy - and What to Do About It." Communications of the ACM 61 (7): 15-17.

Kuhn, Thomas. 1962. The Structure of Scientific Revolutions. Chicago: University of Chicago Press.

LaPointe, Cara, and Lara Fishbane. 2018. "The Blockchain Ethical Design Framework." innovations 12 (3): 50-71.

Lucchi, Nicola. 2016. The Impact of Science and Technology on the Rights of the Individual. (Law, Governance and Technology 26). Cham: Springer.

Mathis, Klaus, and Avishalom Tor, eds. 2016. Nudging - Possibilities, Limitations and Applications in European Law and Economics. Cham: Springer. Nida-Rümelin, Julian. 2011. Verantwortung. Leipzig: Reclam.

Polrot, Simon. 2017. “Blockchain': State of the Art and Prospective." Published January 31, 2017. https://medium.com/@si-monpolrot/blo ckchain-state-of-the-art-and-prospective-4777e329df14.

PriceWaterhouseCoopers. 2016. “The Un(der)banked is FinTech's Largest Opportunity." DeNovo Q2 2016 FinTech ReCap and Funding ReView. Rainey, Stephen, and Philippe Goujon. 2011. "Toward a normative ethics for technology development." Journal of Information 9 (3): 157-179.

Reiijers, Wessel, and Mark Coeckelbergh. 2018. "The Blockchain as a Narrative Technology: Investigating the Social Ontology and Normative Configurations of Cryptocurrencies." Philosophy \& Technology 31 (1): 103-130.

Sacks, Jonathan. 2015. "Sword Into Plowshares." The Wall Street Journal Review, October 3-4, 2015: C1-C2.

Seele, Peter. 2016. "Digitally unified reporting how XBRL-based real-time transparency helps in combining integrated sustainability reporting and performance control." Journal of Cleaner Production 136 (Part A), 65-77. 
Seele, Peter. 2018. "Let Us Not Forget: Crypto Means Secret. Cryptocurrencies as Enabler of Unethical and Illegal Business and the Question of Regulation." Humanist Management Journal 3: 133-9.

Shibasaki, Fumikazu. 2005. "Technology and ethics." Philosophy \& Criticism 31 (18): 487-498.

Morgan Stanley. 2018. "Power Play: What Impact Will Cryptocurrencies Have on Global Utilities?” Published January 17, 2018. https://www.mo rganstanley.com/ideas/cryptocurrencies-global-utilities

Steiner, Jutta. 2015. "Blockchain Can Bring Transparency to Supply Chains. The Business of Fashion.” Published June 19, 2015. http://w ww.businessoffashion.com/articles/opinion/op-ed-blockchain-can-bring-t ransparency-to-supply-chains.

Storino, John R., Justin C. Steffen, and Matthew T. Gordon. 2017. "Decrypting the Ethical Implications of Blockchain Technology." Legaltech News (November 13, 2017).

Swan, Melanie. 2015. Blockchain. Blueprint for a New Economy. Sebastopol:

O'Reilly Media.

Swan, Melanie, and Primavera De Filippi. 2017. "Toward A Philosophy of Blockchain: A Symposium Introduction.” Metaphilosophy 48 (5): 603619.

UN. 2015. "Deputy Secretary-General, Marking Fiftieth Anniversary of Anti-Racism Convention, Urges Internet to Be Used as Powerful Tool in Fight against Racial Discrimination.” Published December 2, 2015. https://www.un.org/press/en/2015/dsgsm921.doc.htm.

The Wall Street Journal. 2018. "How dirty money disappears into the black hole of cryptocurrency." Published September 28, 2018. https://www.wsj .com/articles/how-dirty-money-disappears-into-the-black-hole-of-cryptoc urrency-1538149743.

Wallach, Wendell, and Collin Allen. 2009. Moral Machines: Teaching Robots Right From Wrong. Oxford: Oxford University Press.

Wallach, Wendell, Collin Allen, and Iva Smith. 2008. "Machine Morality: Bottom-up and Top-down Approaches for Modeling Human Moral Faculties." AI \& Society 22 (4): 565-82.

The Washington Post. 2018. "The cryptocurrency-terrorism connection is too big to ignore." Published December 17, 2018. https://www.washingt onpost.com/opinions/the-cryptocurrency-terrorism-connection-is-too-bi 
g-to-ignore/2018/12/17/69ed6ab4-fe4b-11e8-83c0-b06139e540e5_stor y.html?noredirect=on\&utm_term $=. d 54 \mathrm{c} 66 \mathrm{c} 1 \mathrm{e} 78 \mathrm{a}$.

Winner, Langdon. 1980. "Do Artifacts Have Politics?” Daedalus 109 (1): 121-136. 
